\title{
Prevalence of Viral Hepatitis in Pregnant Women in the Republic of Sakha (Yakutia)
}

\author{
Snezhana S. Sleptsova, PhD, ScD ${ }^{1}$; Natalia I. Douglas, $\mathrm{PhD}, \mathrm{ScD}^{1}$; Yana G. Rad, $\mathrm{PhD}^{1}$; \\ Tatyana E. Burtseva, PhD, ScD ${ }^{1,2 *}$; Nikolai M. Gogolev, $\mathrm{PhD}^{1}$; Diana A. Makaeva, $\mathrm{PhD}^{3}$ \\ ${ }^{1}$ M. K. Ammosov North-Eastern Federal University, Yakutsk, the Russian Federation \\ ${ }^{2}$ Yakut Science Center of Complex Medical Problems, Yakutsk, the Russian Federation \\ ${ }^{3}$ Moscow Regional Perinatal Center, Moscow, the Russian Federation
}

\begin{abstract}
The prevalence of viral hepatitis in pregnant women in the Republic of Sakha (Yakutia) (RS(Y)) for 2007-2016 is presented in this article. (International Journal of Biomedicine. 2017;7(3):236-239.)
\end{abstract}

Key words: chronic hepatitis $\mathrm{B} \bullet$ chronic hepatitis $\mathrm{C} \bullet$ mother-to-child transmission $\bullet$ vaccination

\section{Abbreviations}

AHB, acute hepatitis B; CVH, chronic viral hepatitis; CHB, chronic hepatitis B; CHC, chronic hepatitis C; CHD, chronic hepatitis D; HCV, hepatitis C virus; HBV, hepatitis B virus; MTCT, mother-to-child transmission

\section{Introduction}

The Republic of Sakha (Yakutia) is a disadvantaged region with a high incidence of viral hepatitis. ${ }^{(1,2)}$ In 2016, according to the register of chronic viral hepatitis $(\mathrm{CVH})$, 14,391 cases of $\mathrm{CVH}$, excluding virus carriers of hepatitis B (570 people), were registered in the Republic of Sakha (Yakutia) [RS(Y)]: CHB - 6404, CHC - 6224, CHD - 889, chronic hepatitis of mixed etiology - 821, and unknown etiology -57 , including 544 patients with liver cirrhosis and 59 patients with primary liver cancer. Thus in the overall structure of $\mathrm{CVH}, \mathrm{HBV}$ infection was dominant, amounting to $44 \%$ of case. ${ }^{(2,3)} \mathrm{HBV}$ infection is the most common form of chronic hepatitis worldwide and a potentially preventable global health problem. The World Health Organization (WHO) estimates more than 2 billion people have been infected with HBV, 360 million people are chronically infected, and 600000 people die annually from complications of HBV-related liver disease. ${ }^{(4)}$

*Corresponding author: Tatyana E. Burtseva, PhD, ScD. Yakut Science Center of Complex Medical Problems, Yakutsk, the Russian Federation. E-mail: bourtsevat@yandex.ru
In endemic regions, perinatal transmission of the virus is of great importance in the spread of HBV infection: $25 \%$ of carriers are infected in the perinatal period. ${ }^{(5-9)}$ Of the many ways of transmitting infection, adverse outcomes often occur when infections develop through sexual contact and from mother to fetus, which require the development of effective measures to prevent transmission pathways, especially mother-to-child transmission (MTCT). MTCT is responsible for more than one third of chronic HBV infections worldwide. An estimated $15 \%-40 \%$ of persons chronically infected develop HBV-related complications, such as cirrhosis and hepatic carcinoma, and $25 \%$ die from these complications. MTCT can occur during pregnancy or during delivery. ${ }^{(10)}$

The aim of the study was to investigate the prevalence of viral hepatitis in pregnant women in RS(Y).

\section{Materials and Methods}

For the retrospective epidemiological analysis, we used the data of the official statistics of RS(Y) and the Center of Hygiene and Epidemiology of RS(Y). To estimate the prevalence of $\mathrm{HBV}$ and $\mathrm{HCV}$ infections in $\mathrm{RS}(\mathrm{Y})$, we used the 
data of the official register, and we analyzed the histories of pregnancy and childbirth at the National Center of Medicine (Yakutsk). A complete range of clinical, laboratory and instrumental, serological, and molecular-biological methods was evaluated.

\section{Results and Discussion}

Our estimation of acute viral hepatitis (B and C) between 2007 and 2016 showed a significant reduction in the incidence of these forms. In 2016, the incidence rate of AHB was 0.52 per 100,000, which was 9.1 times less than in 2007 . Since 2012, the incidence of AHC has increased by $1.45 \%$, compared to 2012 (Fig.1). The reduction in the incidence can be explained by the introduction of the compulsory vaccination against HBV and improvement of a complex of measures aimed at preventing the parenteral transmission of infection in health institutions and institutions of non-medical profile, strengthening the fight against drug abuse, increasing public awareness of how HBV and HCV infection are transmitted and how to prevent infection from these viruses. ${ }^{(1)}$

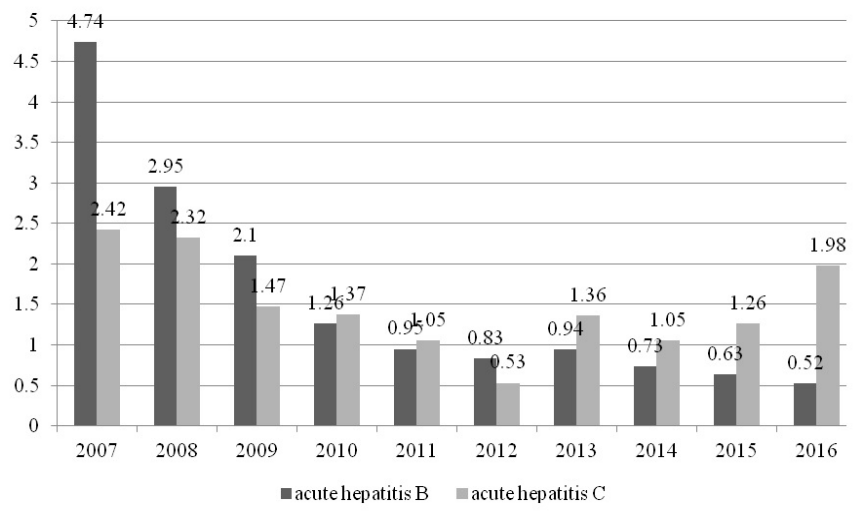

Fig. 1. The incidence rate of $A H B$ and $A H C$ in $R S(Y)$ between 2007 and 2016 (per 100,000 population).

The frequency of pregnant women with HBs antigenemia in the territory of RS(Y) in 2005-2011 ranged from 3.1\% to $3.9 \%$; the total of 234,140 samples of sera were examined and HBsAg was identified in 7646(3.27\%). Despite this, the absolute number of the seropositive persons with HBV infection increased by 1.9 times from 2005 to 2011 (Fig. 2).

Against the background of the specific immunization, the level of HBsAg carriage among children up to 14 years of age decreased from 86.3 per 100,000 in 2000 to 0.49 per 100,000 in 2011, which demonstrated the effectiveness of vaccination against $\mathrm{HBV}$ infection, as evidenced by a very high inverse correlation $(\mathrm{r}=-0.96, \mathrm{P}<0.001)$ between the indicators of $\mathrm{HBsAg}$ carriage and vaccination coverage.

However, the incidence of CVHs B and C has no tendency to decrease. In the period from 2007 to 2009, the incidence of CHB increased, achieving the maximum level of 39.3 cases per 100,000 population. From 2010 to 2014, the incidence of CHB decreased to $27.8 \%$, but since 2015 , the incidence of CHB has again started increasing, up to $37.1 \%$ in 2016 (Fig. 3).

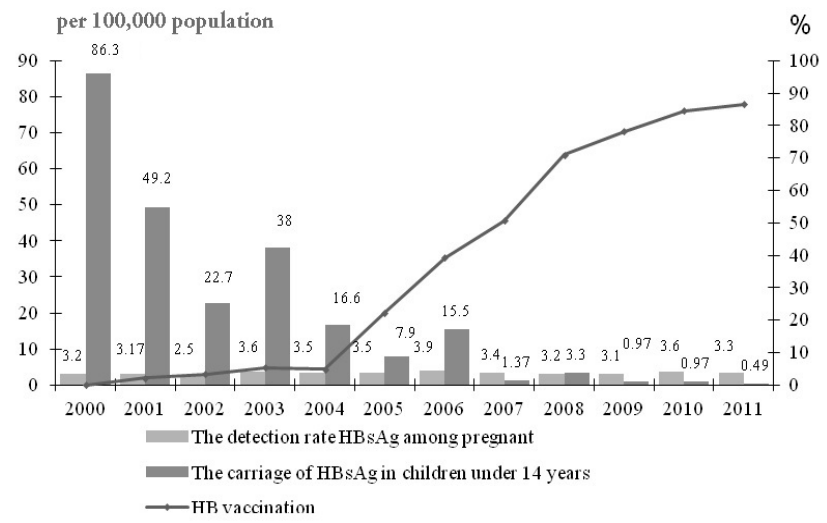

Fig. 2. The detection rate of $H B s A g$ among pregnant women and the level of HBsAg carriage among children up to 14 years of age against the background of $H B V$ vaccination in $R S(Y)$.

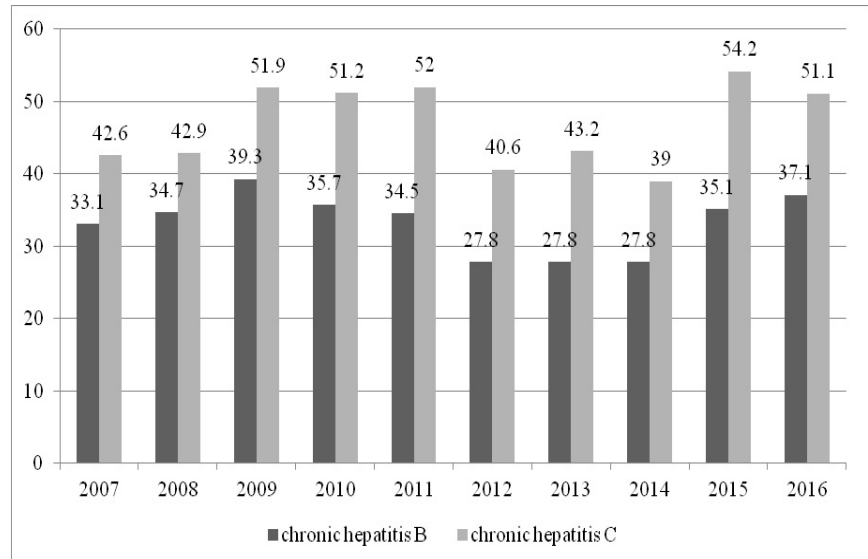

Fig. 3. The incidence of $C V H s$ s and $C$ in $R S(Y)$ between 2007-2016 (per 100,000 population).

Thus, the detection of HBsAg among pregnant women in the period 2007 to 2016 ranged from $3.4 \%$ to $2.1 \%$ (Fig. 4 ). HBsAg was detected in 16,359(3.9\%) out of 422,272 serum samples. The detection rate of antibodies to HCV among pregnant women during this period revealed that $1.3 \%$ of women surveyed were anti-HCV positive. Thus, HBsAg among pregnant women was 3.0 times more prevalent than antibodies to hepatitis $\mathrm{C}$.

In the period between 2007 and 2017, the detection of HBsAg in newborns from women with symptomatic HBV infection and women with asymptomatic forms of $\mathrm{HBV}$ infection constituted $2.1 \%$ on average and fluctuated in different years from 0 to $15 \%$. In the previous period, from 2000 to 2003, an examination of 1832 newborns at high risk for HBV infection found HBsAg in $120(6.5 \%)$ children. The decrease in this indicator demonstrates the effectiveness of specific prevention guards; the rate of anti-HCV among infants did not show a trend towards reduction..$^{(1,11)}$

The results of newborn screening for HBV infection has to be compared with the dynamics of the incidence of this 
infection in children during the first year of life. Therefore, in $\mathrm{RS}(\mathrm{Y})$ among groups of children up to 1 year in the period between 2003 and 2010, there were no cases of acute hepatitis, but HBsAg carriage was identified. In 2011 and 2012, 2 cases of acute hepatitis B (one for each year) were identified in children under 1 year born to mothers with active $\mathrm{HBV}$ infection. This fact confirms the need for comprehensive examination of children born to HBsAg-positive mothers, and for an individualized approach to immunization and subsequent longitudinal research data for children up to 1 year.

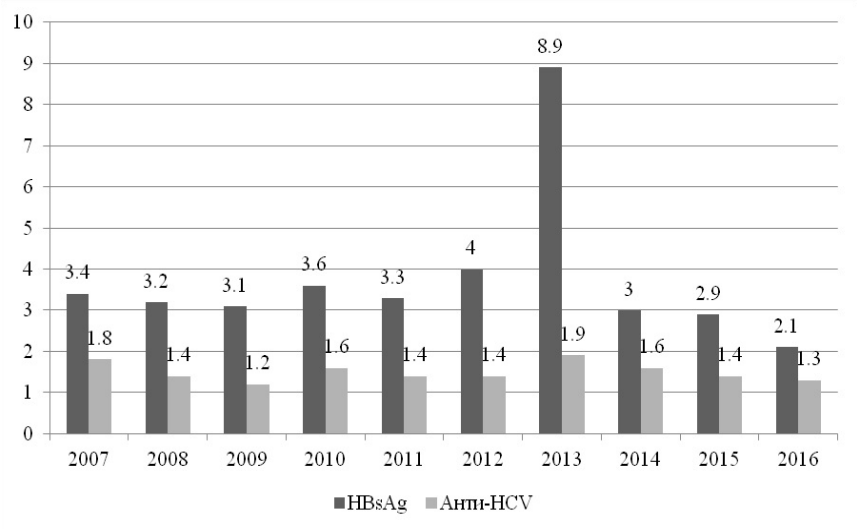

Fig. 4. The detection rate of HBsAg and antibodies to $H C V$ among pregnant women in RS(Y) between 2007 and $2016(\%)$.

In $\mathrm{RS}(\mathrm{Y})$, pregnant women in antenatal clinics undergo an examination for the presence of serum markers of viral hepatitis B and C. Upon detection of HBsAg, all sera are subjected to HBV DNA by PCR, as well as HBsAg and $\mathrm{HBeAg}$ quantification by the chemiluminescent immunoassay method. In addition, it is recommended to perform a liver fibroelastometry.

All pregnant women with $\mathrm{HBV}$ infection have to be included in the national registry for CVHs, and thereafter, dynamic monitoring has to be performed, with the necessary complex of diagnostic measures and, according to the indications, antiviral therapy has to be performed.

Acute viral hepatitis in pregnant women usually manifests with more pronounced symptoms than in nonpregnant women. According to A.Rakhmanova, ${ }^{(5)}$ there were no deaths from HAV infection; all deaths were due to HBV infection. In total, over the past 3 years, maternal mortality due to viral hepatitis has had a tendency to decrease from $1.79 \%$ to $0.21 \%$.

All newborns born to women with HBsAg undergo vaccination on an individual scheme according to G. Poland et al. ${ }^{(12)}$ According to Global Hepatitis Report (WHO), infants born to mothers who are positive for both HBsAg and HBeAg are at a higher risk of acquiring infection (transmission risk $70 \%-100 \%$ in Asia and $40 \%$ in Africa) than those born to HBsAg-positive mothers who have lost the $\mathrm{HBeAg}(5 \%-30 \%$ in Asia and 5\% in Africa). ${ }^{(13)}$ Caesarean section reduces the perinatal transmission of $\mathrm{HBV}$ infection from $\mathrm{HBsAg}$-positive women to their infants. ${ }^{(14)}$
The basis of prevention of perinatal HBV infection is an active vaccination and passive immunization with hepatitis $\mathrm{B}$ immune globulin, which protect newborns from infection in 90\%-95\% of cases.

Vaccination is the most effective measure to reduce the global incidence of hepatitis B. In 1991, the World Health Organization (WHO) recommended that all countries introduce a policy of universal hepatitis $\mathrm{B}$ vaccination to prevent and control HBV infection and its long term sequelae on a global scale. Compared to other healthcare interventions, vaccination is an economically advantageous option, both in terms of cost-effectiveness and benefit-cost ratios. ${ }^{(15)} \mathrm{WHO}$ recognizes the importance of hepatocellularcarcinoma and other HBV-related diseases as global public health problems and reiterates its recommendation that hepatitis $\mathrm{B}$ vaccines should be included in national immunization programmes. ${ }^{(16)}$

\section{Conclusion}

Thus, because of active vaccination and passive immunization, there is a trend to reduce the incidence of HBV infection; however, the incidence rate is 2-3 times greater than national data. Thus, our study on the prevalence of parenteral viral hepatitis $\mathrm{B}$ and $\mathrm{C}$ among pregnant women and newborns in $\mathrm{RS}(\mathrm{Y})$ showed that hepatitis B prevalence is still high, indicating a high risk of MTCT of hepatitis B.

Enforced testing for HBsAg of blood donations has to be a universal and important requirement to prevent infections in clinical settings, as well as maintaining asepsis in invasive techniques and vaccination for high-risk groups. Screening pregnant women for HBV infection, providing infant postexposure prophylaxis, and maternal treatment with antiviral medications are strategies for reducing MTCT transmission rates and the global burden of new chronic HBV infections. Administration of hepatitis B immune globulin (HBIG) and hepatitis B (HepB) vaccine within 24 hours of birth, followed by completion of the vaccine series, is a leading way to prevent MTCT. ${ }^{(16)}$ Attaining a better understanding of the mechanisms of MTCT and implementing existing policies on maternal screening and infant follow-up are critical for further reductions in MTCT transmission.

\section{Competing interests}

The authors declare that they have no competing interests.

\section{References}

1. Sleptsova SS. Viral hepatitis in the Sakha Republic (Yakutia) and their role in the development of primary liver cancer. Abstract of ScD Thesis. SPb; 2013. [in Russian].

2. Sleptsova SS, Rakhmanova AG, Douglas NI. The issues of prevention of vertical transmission of hepatitis B in the Republic of Sakha (Yakutia). In Rakhmanova AG, Yakovlev AA, editors. Almanac "Infectious diseases - 2015". St Petersburg: Izd-vo FKh SPbGU; 2015:238-242. [in Russian]. 3. Shek LA, Sleptsova SS, Douglas NI. Strategy of vaccine prophylaxis for HB infection in conditions of epidemiological trouble in the Republic of Sakha (Yakutia). Collection 
of scientific works of the VI Congress with international participation "Ecology and human health in the North." Yakutsk, North-Eastern Federal University named after M.K. Ammosov, November 12-14, 2015. [in Russian].

4. WHO. Hepatitis B. Available from: http://www.who.int/ mediacentre/factsheets/fs204/en/ Accessed June 22, 2014.

5. Rakhmanova AG, Yakovlev AA. Chronic viral hepatitis and HIV infection SPb.: "VVM"; 2011. [in Russian].

6. Wong S, Chan LY, Yu V, Ho L. Hepatitis B carrier and perinatal outcome in singleton pregnancy. Am J Perinatol. 1999;16(9):485-8.

7. Wiseman E, Fraser MA, Holden S, Glass A, Kidson BL, Heron LG, et al. Perinatal transmission of hepatitis B virus: an Australian experience. Med J Aust. 2009;190(9):489-92.

8. Yogeswaran K, Fung SK. Chronic hepatitis B in pregnancy: unique challenges and opportunities. Korean $\mathrm{J}$ Hepatol. 2011;17(1):1-8. doi: 10.3350/kjhep.2011.17.1.1.

9. Stevens CE, Toy PT, Tong MJ, Taylor PE, Vyas GN, Nair PV, et al. Perinatal hepatitis B virus transmission in the United States: prevention by passive-active immunization. JAMA.1985;253(12):1740-5.

10. Nelson NP, Jamieson DJ, Murphy TV. Prevention of Perinatal Hepatitis B Virus Transmission. J Pediatric Infect Dis Soc. 2014; 3 Suppl 1: S7-S12. doi: 10.1093/jpids/piu064
11. Sleptsova S, Duglas NI, Shek L. Clinical case of conducting pregnancy and childbirth at the woman with chronic viral hepatitis B in the replicative form. Wiad Lek. 2015;68(4):591-5.

12. Poland GA. Evaluating existing recommendations for hepatitis A and B vaccination. Am J Med. 2005; 118 Suppl 10A:16S-20S.

13. Global Hepatitis Report, World Health Organization, Geneva, 2017. Available from: http://apps.who.int/iris/bitstre am/10665/255016/1/9789241565455-eng.pdf?ua=1, accessed May 2017.

14. Pan CQ, Zou HB, Chen Y, Zhang X, Zhang H, Li J, Duan Z.Clin Cesarean section reduces perinatal transmission of hepatitis B virus infection from hepatitis B surface antigenpositive women to their infants. Gastroenterol Hepatol. 2013;11(10):1349-55. doi: 10.1016/j.cgh.2013.04.026.

15. Franco E, Bagnato B, Marino MG, Meleleo C, Serino L, Zaratti L. Hepatitis B: Epidemiology and prevention in developing countries. World J Hepatol. 2012;4(3):74-80. doi: 10.4254/wjh.v4.i3.74.

16. World Health Organization. Hepatitis B vaccines: WHO position paper, July 2017 - Recommendations. Vaccine. 2017 Jul 22. pii: S0264-410X (17) 30954-4. doi: $10.1016 /$ j.vaccine.2017.07.046. 